\title{
Single-cannula, single-incision thoracoscopic anatomic segmentectomy after pneumonectomy
}

\author{
Gregor J. Kocher, MD, ${ }^{\mathrm{a}}$ Adrian Zehnder, MD, ${ }^{\mathrm{a}}$ Gabor Erdoes, MD, ${ }^{\mathrm{b}}$ Christian Seidl, MD, ${ }^{\mathrm{b}}$
}

Bernhard Winkler, MD, ${ }^{\mathrm{c}}$ and Ralph A. Schmid, MD, ${ }^{\mathrm{a}}$ Bern, Switzerland

\footnotetext{
From the ${ }^{\mathrm{a}}$ Division of General Thoracic Surgery, and Departments of ${ }^{\mathrm{b}}$ Anesthesiology and Pain Therapy and ${ }^{\mathrm{c} C}$ Cardiovascular Surgery, Bern University Hospital, University of Bern, Bern, Switzerland.

Disclosures: Authors have nothing to disclose with regard to commercial support.

Received for publication Jan 24, 2017; revisions received March 23, 2017; accepted for publication March 28 , 2017; available ahead of print April 25, 2017.

Address for reprints: Gregor J. Kocher, MD, Division of General Thoracic Surgery, University Hospital Bern, Bern CH - 3010, Switzerland (E-mail: gregor.kocher@insel.ch).

J Thorac Cardiovasc Surg 2017; 154:e29-31 $0022-5223 / \$ 36.00$

Copyright (C) 2017 by The American Association for Thoracic Surgery http://dx.doi.org/10.1016/j.jtcvs.2017.03.127
}

Video clip is available online.

Lung resections after pneumonectomy have been described in the literature as a treatment option for patients with metachronous or metastatic bronchial carcinoma. ${ }^{1}$ With the increased use and advances in extracorporeal membrane oxygenation (ECMO), a case of anatomic segmental resection via thoracotomy after contralateral pneumonectomy on venoarterial ECMO has been reported. ${ }^{2}$ With the aim of further reducing the invasiveness of the procedure, we not only used a single-incision thoracoscopic approach for an anatomic apical segmental resection in the following case but also reduced the invasiveness of ECMO by using a single cannula venovenous ECMO.

\section{CASE REPORT}

Written informed consent was obtained from the patient. The now 60-year-old male patient was diagnosed with intimal sarcoma of the left central pulmonary artery in 2003. The tumor was resected with an extended left-sided pneumonectomy with resection and subsequent bioprosthetic reconstruction of the pulmonary valve on extracorporeal circulatory support in 2003. In 2016, a solitary pulmonary nodule measuring $2 \times 3 \mathrm{~cm}$ in the central aspect of the superior segment of the right lung was seen (Figure 1, $A$ ), and bronchoscopic biopsy confirmed the diagnosis of a metastasis of the patient's known angiosarcoma. Further metastases were excluded by positron emission tomography (Figure 1, B). In regard to the patient's excellent condition with a cardiopulmonary exercise test result of a maximal oxygen

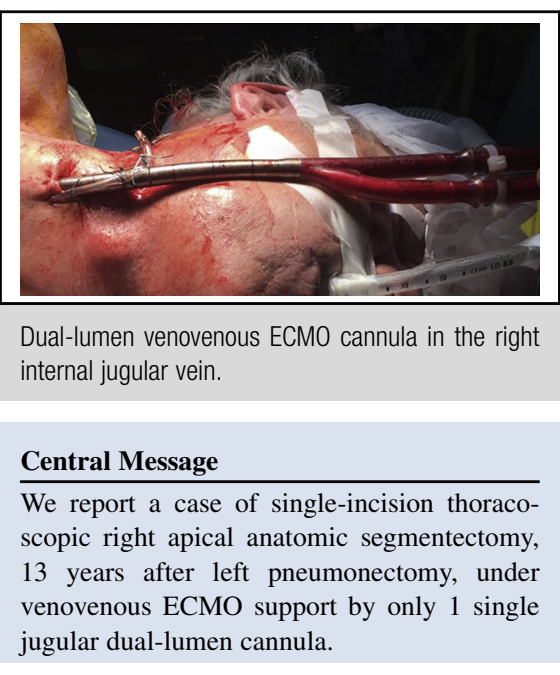

See Editorial Commentary page e33.
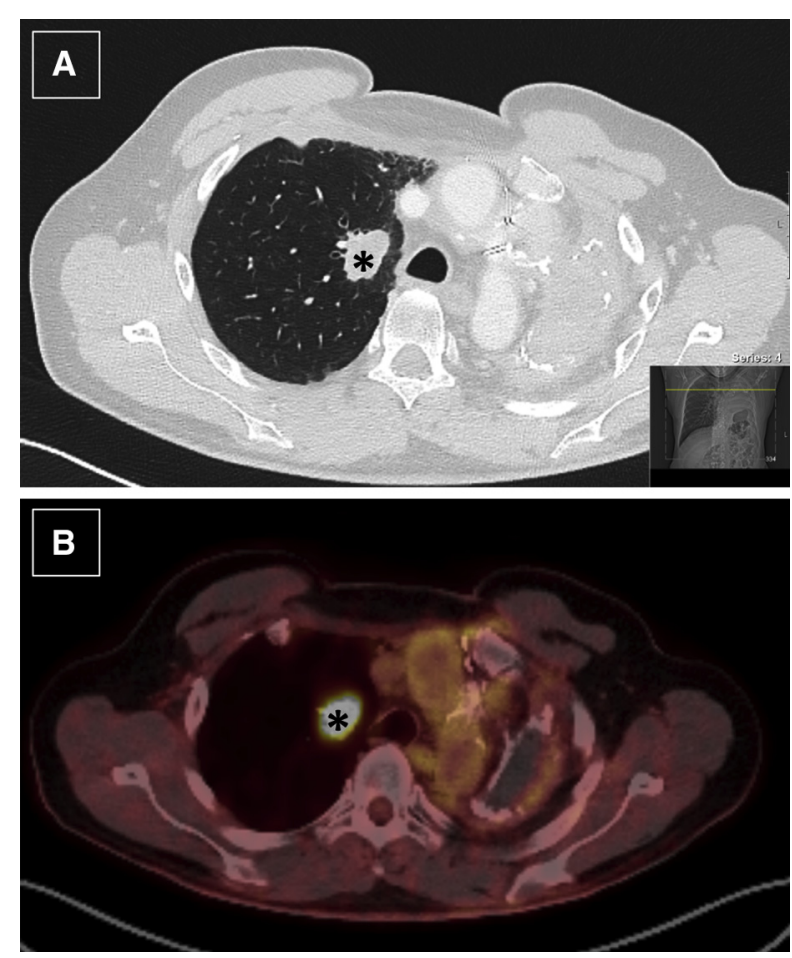

FIGURE 1. Chest computed tomography (A) and positron emission tomography (B) showing the metastasis in the apical segment of the right upper lobe (marked with asterisk). 

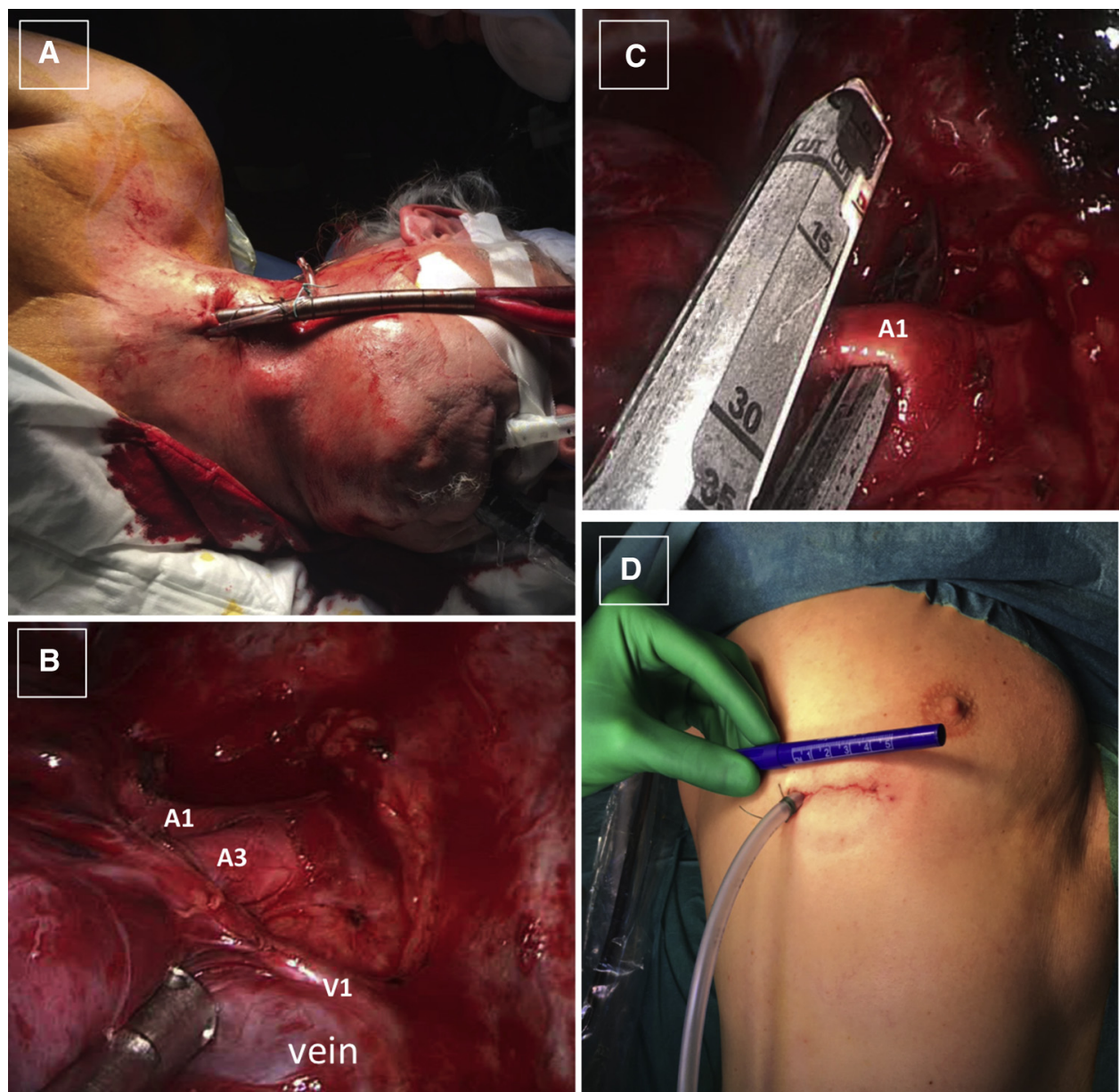

FIGURE 2. A, Venovenous ECMO cannula positioned in the right internal jugular vein. B, Intraoperative view of the upper lobe vein including its V1 branch and the superior trunk of the pulmonary artery with its branches A1 and A3. C, Division of the A1 arterial branch by means of a stapling device. $\mathrm{D}$, Postoperative view of the 4-cm skin incision in the right inframammary fold.

consumption of $24 \mathrm{~mL} \times \mathrm{kg}^{-1} \times \min ^{-1}(78 \%)$, our multidisciplinary tumor board panel advocated for a surgical approach.

In November 2016, the patient was put under general anesthesia after prior placement of a thoracic epidural catheter, and standard monitoring including regional cerebral oxygen saturation was installed. A 31F Avalon Elite Bi-Caval Dual Lumen Catheter (Maquet Cardiopulmonary GmbH, Rastatt, Germany) was inserted into the superior vena cava and positioned under transesophageal echocardiographic control (Figure 2, A). After the administration of $5000 \mathrm{IU}$ heparin, the ECMO circuit was initiated and the patient was cooled down to an esophageal temperature of $34^{\circ} \mathrm{C}$.

The patient was put in a left lateral decubitus position. A 4-cm incision in the inframammary fold in the fifth intercostal space was made, and the chest cavity was entered with a $10-\mathrm{mm}, 30^{\circ}$ angled thoracoscope. After taking down some adhesions, the hilar structures were dissected and the segmental artery, vein, and bronchus were divided individually by means of a stapling device (Echelon Flex Powered Vascular Stapler; Ethicon, Johnson \& Johnson, Zug, Switzerland) (Video 1, Figure 2). The segmental plane was subsequently divided with an endostapler (Echelon Flex Powered Endopat Stapler,

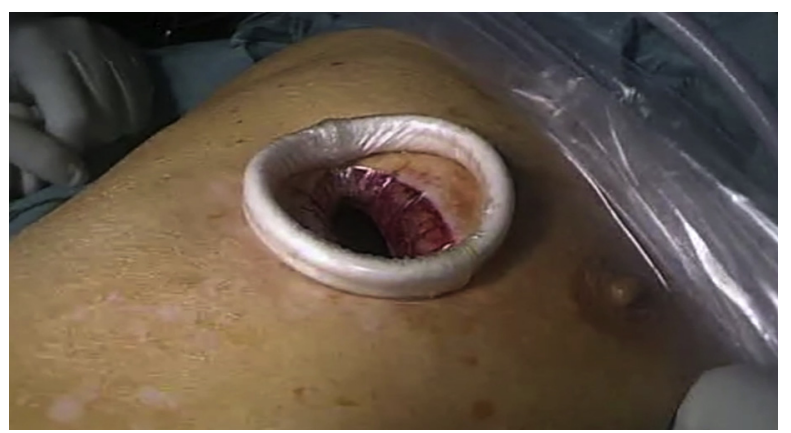

VIDEO 1. The main intraoperative steps of the surgical procedure. Video available at: http://www.jtcvsonline.org/article/S0022-5223(17)30648-7/ addons. 
Ethicon, Johnson \& Johnson). A $24 \mathrm{~F}$ chest tube was inserted through the incision, and ventilation was started again with good reexpansion of the whole lung. After closure of the incision, the patient was rewarmed to $36^{\circ} \mathrm{C}$ and weaned off the ECMO with subsequent removal of the ECMO cannula and extubation of the patient in the operating room. Postoperative recovery was uneventful with removal of the chest drain on the second postoperative day and patient discharge on postoperative 5. So far, 1 month after surgery, the patient is in good condition without respiratory problems or any signs of recurrence.

\section{DISCUSSION}

To our knowledge, this is the first reported case of a single-incision thoracoscopic segmentectomy after contralateral pneumonectomy. Furthermore, in this setting the use of a single dual-lumen cannula for venovenous ECMO support is a complete novelty.

Experience with the use of ECMO to support oxygenation during pulmonary resection in patients with borderline lung function is growing. ${ }^{3}$ ECMO has the potential to allow life-prolonging thoracic surgical procedures in patients with metachronous non-small cell lung cancer and patients with localized pulmonary metastasis who would otherwise not tolerate surgery using conventional ventilation. With the use of a single jugular venous access for venovenous ECMO, the invasiveness and risk of complications may be further decreased compared with conventional ECMO access, ${ }^{4}$ although it has to be considered that positioning of the dual-lumen catheter is more complex compared with conventional venovenous ECMO. ${ }^{5}$
In addition to the minimally invasive ECMO approach, the minimally invasive surgical approach resulted in minimal postoperative pain and a short hospital stay despite the complexity of the whole procedure in the described case.

\section{CONCLUSIONS}

Even patients undergoing pneumonectomy can undergo curative or at least life-prolonging thoracic surgical procedures in selected cases. Although ECMO can ensure sufficient oxygenation and decarboxylation during complex surgical procedures, minimally invasive surgical approaches can further minimize tissue trauma and morbidity in such patients.

\section{References}

1. Toufektzian L, Patris V, Potaris K, Konstantinou M. Is it safe and worthwhile to perform pulmonary resection after contralateral pneumonectomy? Interact Cardiovasc Thorac Surg. 2015;20:265-9.

2. Heward E, Hayes T, Evison M, Booton R, Barnard J, Shah R. Extracorporeal membrane oxygenation assisted segmentectomy for metachronous lung cancer after pneumonectomy. Ann Thorac Surg. 2016;102:e187-9.

3. Redwan B, Ziegeler S, Freermann S, Nique L, Semik M, Lavae-Mokhtari M et al. Intraoperative veno-venous extracorporeal lung support in thoracic surgery: a single-centre experience. Interact Cardiovasc Thorac Surg. 2015; 21:766-72.

4. Bisdas T, Beutel G, Warnecke G, Hoeper MM, Kuehn C, Haverich A, et al Vascular complications in patients undergoing femoral cannulation for extracorporeal membrane oxygenation support. Ann Thorac Surg. 2011;92: 626-31.

5. Kuhl T, Michels G, Pfister R, Wendt S, Langebartels G, Wahlers T. Comparison of the Avalon dual-lumen cannula with conventional cannulation technique for venovenous extracorporeal membrane oxygenation. J Thorac Cardiovasc Surg. 2015;63:653-62. 